\title{
Endoscopic band ligation in the treatment of gastric antral vascular ectasia: a systematic review and meta-analysis
}

다 (i)

\author{
Authors \\ Thomas R. McCarty, Kelly E. Hathorn, Walter W. Chan, Kunal Jajoo
}

Institution

Division of Gastroenterology, Hepatology, and Endoscopy. Brigham and Women's Hospital. Harvard Medical School, Boston, Massachusetts, United States

submitted 27.11.2020

accepted after revision 15.2.2021

Bibliography

Endosc Int Open 2021; 09: E1145-E1157

DOI 10.1055/a-1401-9880

ISSN 2364-3722

(c) 2021. The Author(s).

This is an open access article published by Thieme under the terms of the Creative Commons Attribution-NonDerivative-NonCommercial License, permitting copying and reproduction so long as the original work is given appropriate credit. Contents may not be used for commercial purposes, or adapted, remixed, transformed or built upon. (https://creativecommons.org/licenses/by-nc-nd/4.0/)

Georg Thieme Verlag KG, Rüdigerstraße 14,

70469 Stuttgart, Germany

Corresponding author

Kunal Jajoo, MD, Division of Gastroenterology, Hepatology and Endoscopy, Brigham and Women's Hospital, 75 Francis Street, Boston, MA 02115, USA

Fax: +1-617-732-7407

kjajoo@bwh.harvard.edu

Supplementary material is available under https://doi.org/10.1055/a-1401-9880

\section{ABSTRACT}

Background and study aims While argon plasma coagulation (APC) is the first-line treatment for gastric antral vascular ectasia (GAVE), endoscopic band ligation (EBL) has shown promising results. The aim of this study was to perform a systematic review and meta-analysis to evaluate the effectiveness of EBL for the treatment of GAVE.

Methods Individualized search strategies were developed in accordance with PRISMA and MOOSE guidelines through September 1, 2020. Measured outcomes included endoscopic success (defined as GAVE eradication/improvement), change in hemoglobin, transfusion dependency, number of treatment sessions, adverse events, rebleeding, and bleeding-associated mortality. Outcomes were compared among studies evaluating EBL versus APC.

Results Eleven studies ( $n=393 ; 59.39 \%$ female; mean age $58.65 \pm 8.85$ years) were included. Endoscopic success was achieved in $87.84 \%$ [ $(95 \% \mathrm{Cl}, 80.25$ to 92.78$\left.) ; 1^{2}=11.96 \%\right]$ with a mean number of $2.50 \pm 0.49$ treatment sessions and average of $12.40 \pm 3.82$ bands applied. For 8 studies comparing EBL $(n=143)$ versus APC $(n=174)$, there was no difference in baseline patient characteristics. However, endoscopic success was significantly higher for EBL [OR 6.04 (95\% Cl 1.97 to $18.56 ; P=0.002$ ], requiring fewer treatment sessions $(2.56 \pm 0.81$ versus $3.78 \pm 1.17 ; P<0.001)$. EBL was also associated with a greater increase in post-procedure hemoglobin [mean difference 0.35 (95\% Cl 0.07 to 0.62 ; $P$ $=0.0140$ ], greater reduction in transfusions required [mean difference -1.46 ( $95 \% \mathrm{Cl}-2.80$ to $-0.12 ; P=0.033$ ], and fewer rebleeding events [OR $0.11(95 \% \mathrm{Cl}, 0.04$ to 0.36$)$; $P<0.001]$. There was no difference in adverse events or bleeding-associated mortality $(P>0.050)$.

Conclusions EBL appears to be safe and effective for treatment of GAVE, with improved outcomes when compared to APC.

\section{Introduction}

Gastric antral vascular ectasia (GAVE) is characterized by a collection of dilated submucosal vessels as well as tortuous capillaries within the mucosal layer of the stomach, typically found within the gastric antrum [1,2]. While the exact pathophysiology of GAVE remains less clear, several potential theories have been proposed: mechanical stress, abnormal antral motility, hypergastrinemia-associated hormonal imbalances, or vasoactive mediators [1,3-6]. Endoscopically, common findings of GAVE include erythematous or hemorrhagic lesions, described as having a linear streaking or punctate appearance, leading to the classic description as watermelon stomach or a honeycomb appearance, respectively [7-10]. Although GAVE remains a re- 
latively infrequent cause of overt gastrointestinal bleeding, persistent iron deficiency with transfusion-dependent anemia are not uncommon among patients with this condition [1113].

Currently, thermal therapy with argon plasma coagulation (APC) remains a first-line endoscopic treatment strategy, though emerging data has suggested patients receiving treatment with radiofrequency ablation (RFA) may have improved outcomes including improved endoscopic success rates, fewer treatment sessions required, and lower rates of adverse events [14-18]. Most studies have demonstrated APC and RFA to have an endoscopic success rate from $70 \%$ to $90 \%$ overall [18]. However, while these success rates up to $90 \%$ are impressive with thermal therapy, it is important to highlight that these treatment strategies act mostly upon the mucosal layer, with limited ability to penetrate to the deeper submucosal layer [19].

Given our current understanding of GAVE, with involvement of both the mucosal and submucosal layer, it stands to reason that treatment techniques designed to act upon both gastrointestinal layers may be a more effective strategy [19]. One such treatment strategy, which is already the mainstay treatment for esophageal varices, is endoscopic band ligation (EBL). This nonthermal endoscopic treatment options affords the ability to treat dilated submucosal veins in addition to the tortuous capillaries of the mucosal layer associated with GAVE. Yet, despite this strategy already being familiar to endoscopists and perhaps mechanistically more plausible as a treatment modality, there remains limited data and poor adoption of this technique as both a first-line strategy or salvage therapy.

As such, the primary aim of this study was to perform a structured systematic review and meta-analysis of all eligible studies to evaluate the effectiveness and safety of EBL in the treatment of GAVE. Additional aims were to compare clinical outcomes of EBL versus thermal endoscopic therapies.

\section{Materials and methods}

\section{Study design}

This study was prospectively submitted in PROSPERO, an international database of prospectively registered systematic reviews in health and social care. The Preferred Reporting Items for Systematic Reviews and Meta-Analyses (PRISMA) statement outline and Meta-Analysis of Observational Studies in Epidemiology (MOOSE) reporting guidelines for reporting systematic reviews and meta-analyses was used to report findings (Appendix 1 and Appendix 2) [20,21].

\section{Literature search}

Two authors (TRM and KEH) independently conducted a comprehensive literature review using a standardized protocol to identify articles that evaluated EBL for the treatment of GAVE. Systematic searches of PubMed, EMBASE, Web of Science, and the Cochrane Library databases were performed from inception through September 1, 2020. Literature search terms included: "gastric antral vascular ectasia (GAVE)" and "endoscopic band ligation (EBL)". After preliminary search results were obtained and duplicate articles excluded, the titles and abstracts of all potentially relevant studies were screened for eligibility. The reference lists of studies of interest were then manually reviewed to identify additional references through cross-checking bibliographies of retrieved full-text papers.

\section{Study selection criteria}

Included studies were required to investigate the use of $E B L$ for the treatment of GAVE. Any retrospective, prospective, or randomized study involving EBL for treatment of GAVE that reported at least one of the pre-defined outcomes was included. Studies involving alternative endoscopic, medical, or surgical modalities were not included in cases where EBL was specifically excluded. A particular study was excluded if deemed to have insufficient data, as were review articles, editorials, and correspondence letters that did not report independent data. Case series and reported studies with $<8$ patients were excluded. Only adult patients (age $\geq 18$ years) were included with studies including pediatric populations excluded from this analysis.

All relevant English language articles (both full-text and published abstracts) were included regardless of year of publication were included. The titles and abstracts of all potentially relevant studies were screened for eligibility. Two reviewers (TRM and $\mathrm{KEH}$ ) independently screened the titles and abstracts of all the articles according to predefined inclusion and exclusion criteria. Any differences were resolved by mutual agreement and in consultation with the third reviewer (WWC). In the case of studies with incomplete information, contact was attempted with the principal authors to obtain additional data.

\section{Measured outcomes}

Multiple outcome measurements were reported in this systematic review and meta-analysis, including endoscopic success of EBL for the treatment of GAVE, defined as complete eradication or evidence of endoscopic improvement of GAVE on follow-up endoscopy. Additional outcomes included clinical success, as measured by average pre- and post-procedure hemoglobin levels, transfusion and hospitalization requirements before and after procedure, as well rates of rebleeding. Further measured outcomes of interest included adverse events and rebleeding-associated mortality rates. Other measured variables abstracted from the literature included baseline patient characteristics, year of publication, type of publication (i.e., full manuscript, abstract, comparative, or non-comparative study), and duration of follow-up.

\section{Statistical analyses}

This systematic review and meta-analysis was performed by calculating pooled proportions. After appropriate studies were identified through systematic review, the individual study proportion was transformed into a quantity using the Freeman-Tukey variant of the arcsine square root transformed proportion. Then the pooled proportion was calculated as the back transform of the weighted mean of the transformed proportions, DerSimonian-Laird weights for the random effects model [22, 23]. The pooled rates were estimated using random effects models and presented as point estimates (rates) with $95 \%$ confidence intervals (Cls) [24-26]. For pre- and post-procedure 


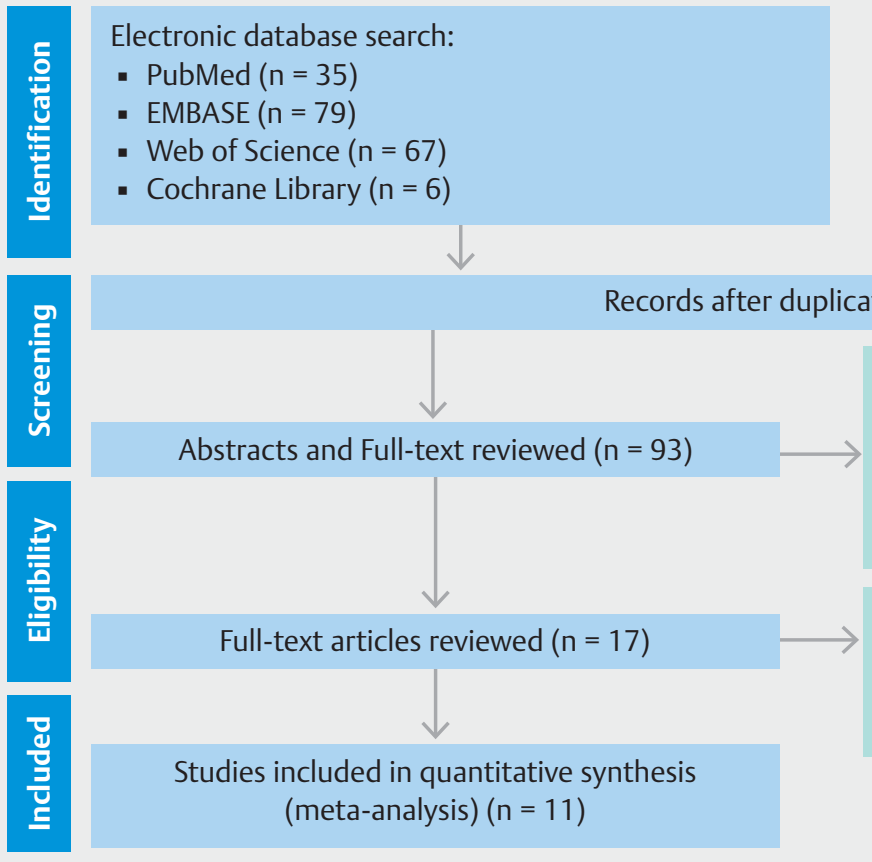

Additional records identified through other sources (i.e., manual abstract search) $(n=4)$

- Fig. 1 Preferred Reporting Items for Systematic Reviews and Meta-Analyses (PRISMA) flowchart of literature search results.

measurements, pooled or weighted mean difference as calculated with corresponding $95 \%$ Cls with corresponding Pvalues.

Additional sensitivity analyses were performed for only randomized controlled trial data (excluding prospective and retrospective studies). Further subgroup analyses were performed for direct comparator studies to compare outcomes between EBL therapy versus APC thermal-based treatment. Again, treatment with alternative thermal therapy, including RFA, was excluded from this study. Mean differences between pre- and post-hemoglobin, transfusion, and hospitalizations were compared along with odds ratios (ORs) calculated to compare additional outcomes between treatment modalities. Univariate meta-regression was also performed to assess measured outcomes for patients with treatment naïve versus APC-refractory GAVE. All calculated $P$ values were 2 -sided, and $P<0.05$ was considered statistically significant. Tabular and graphical analyses were performing using Comprehensive Meta-Analysis software, version 3 (BioStat, Englewood, New Jersey, United States). Combined weighted proportions were determined by use of the Stata 15.0 software package (Stata Corp LP, College Station, Texas, United States).

\section{Risk of bias and quality assessment}

Risk of bias and quality of observational studies was evaluated using the Newcastle-Ottawa Quality Assessment Scale and JADAD score for quality of randomized trials $[27,28]$. In this study, high quality was defined as a Newcastle-Ottawa Quality Assessment Scale score $\geq 4$ or a JADAD score $\geq 3$. Two authors (TRM and $\mathrm{KEH}$ ) independently extracted data and assessed the risk of bias and study quality for each of the articles. Any disagree-
Excluded based on title and abstract review $(n=76)$

- Basic science articles, review articles, editorials

- Observational studies

- Reported non-effective interventions or interventions not used in clinical practice

Full-text articles excluded $(n=6)$

- Review/commentaries

- Insufficient data

- Follow-up of initial study two authors or in consultation with a third author (WCC).

\section{Investigations of heterogeneity and prediction interval}

Heterogeneity was assessed for the individual meta-analyses using the chi squared test and the $R^{2}$ statistic [29]. Significant heterogeneity was defined as $P<0.05$, with $R^{2}>50 \%$ indicating substantial heterogeneity. Further quantification of heterogeneity was categorized based upon $R^{2}$ with values of $25 \%, 50 \%$, and $75 \%$ indicating low, moderate, and high amounts of heterogeneity, respectively. Given the use of random effects model to estimate average effect, a $95 \%$ prediction interval was calculated to determine the dispersion of effects and clearly illustrate heterogeneity in the calculated effect size [30-32].

\section{Publication bias}

To assess for publication bias, a funnel plot was created and visually inspected for asymmetry and quantitatively using Egger regression testing $[33,34]$. The trim and fill method was used to correct for funnel plot asymmetry and provide an adjusted effect [35]. The classic fail-safe test was also applied to assess risk of bias across studies.

\section{Results}

\section{Characteristics of included studies}

This systematic review and meta-analysis included a total of 11 studies $(n=393)$ [36-46]. A PRISMA flow chart of search results is shown in $>$ Fig. 1. Of the 393 patients with GAVE, 219 patients underwent treatment with $\mathrm{EBL}$, with the remaining pa- 
tients receiving thermal therapy with APC. Eight of the 11 included studies were comparative in nature (EBL: $n=143$ versus APC: $n=174)$. Table 1 demonstrates the baseline patient characteristics of included studies. All but two studies were full-text published manuscripts with the remaining being published abstracts from annual gastroenterology scientific meetings. Four prospective, randomized controlled trials, one prospective observational study, and 6 retrospective cohort studies were included with publication years ranging from 2008 to 2020.

\section{Included patient characteristics}

Mean age of included patients who underwent EBL was $58.65 \pm$ 8.85 years. Fifty-nine percent of patients were female. In terms of baseline patient characteristics and presenting symptoms, $71.97 \%$ of patients carried a diagnosis of cirrhosis. More than half $(57.14 \%)$ of patients presented with evidence of overt bleeding at time of EBL. Of studies reporting prior therapies, $37.80 \%$ of patients included in this meta-analysis had refractory GAVE despite prior treatment with APC. The mean followup period was $14.32 \pm 11.10$ months.

\section{Endoscopic success}

The outcome of endoscopic success, defined as complete eradication or improvement in GAVE on follow-up endoscopy, was noted to occur in $87.84 \%$ [(95\% Cl, 80.25 to 92.78$)$; $\left.\right|^{2}=11.96 \%$; prediction interval 72.60 to 95.17 ] ( $>$ Fig. 2a). This was accomplished with a mean number of $2.50 \pm 0.49$ treatment sessions with an average of $12.40 \pm 3.82$ bands applied per treatment session. On sensitivity analysis limited to randomized trials, endoscopic success was achieved in $88.73 \%$ [(95\% Cl, 63.83 to 97.23); $\left.\left.\right|^{2}=59.39 \%\right]$ of patients. Excluding published abstracts, $86.95 \%$ [ $(95 \% \mathrm{Cl}, 78.58$ to 92.37$) ; I^{2}=11.99 \%$ ] demonstrated treatment success endoscopically. Summary data for endoscopic and clinical success of EBL for the treatment of GAVE is highlighted in $>$ Table 2 .

\section{Clinical success}

On average, patients required $2.76 \pm 2.74$ units of red-cell transfusions and were hospitalized $2.06 \pm 0.31$ times prior to EBL. Mean pre-procedure hemoglobin values were $7.66 \pm$ $0.96 \mathrm{gm} / \mathrm{dL}$ with an increase in hemoglobin post-EBL of $2.23 \mathrm{gm} / \mathrm{dL}$ [(95\% Cl, 1.39 to 3.07$\left.) ; \mathrm{I}^{2}=91.00 \% ; P<0.001\right]$ ( $>$ Fig.2b). The number of transfusions decreased significantly post-EBL [weighted mean difference $-1.63 \mathrm{gm} / \mathrm{dL}(95 \% \mathrm{Cl}$, -2.39 to -0.86$\left.) ; I^{2}=89.39 \% ; P<0.001\right]$ as did bleeding-associated hospitalizations [weighted mean difference -1.01 times (95\% Cl, -1.35 to -0.67 ); $\left.\right|^{2}=0.00 \%$; P<0.001] ( Fig. $2 \mathrm{c}$ and - Fig. 2 d). Among randomized controlled trial studies, pooled mean hemoglobin increased $1.48 \mathrm{gm} / \mathrm{dL}[(95 \% \mathrm{Cl}, 0.40$ to 2.56); $I^{2}=93.00 \% ; P=0.007$ ] after treatment with EBL. Further analyses limited to randomized trials, amplified this decrease in transfusions post-EBL [weighted mean difference $-4.28 \mathrm{gm} /$ $\mathrm{dL}(95 \% \mathrm{Cl},-7.22$ to -1.34$\left.) ; I^{2}=94.57 \% ; P=0.004\right]$. Only 2 studies reported hospitalization data pre- and post-EBL, therefore pooled proportions could not be calculated.

\section{Adverse events and bleeding-associated mortality}

Adverse events occurred in $10.90 \%$ [ $(95 \% \mathrm{Cl}, 5.14$ to 21.65$)$; $\mathrm{I}^{2}=38.23 \%$; prediction interval 1.71 to 46.18 ] of patients who underwent EBL. All studies reporting adverse events were fulltext manuscripts. Rebleeding post-EBL occurred in $9.00 \%$ [(95\% Cl, 5.02 to 15.62$) ; \mathrm{I}^{2}=0.00 \%$; prediction interval 4.33 to 17.78] of patients. Among only randomized controlled trials, adverse events were reported among 12.59\% [ $(95 \% \mathrm{Cl}, 4.08$ to $32.82) ; I^{2}=62.29 \%$ ] of cases. Excluding abstracts, the rebleeding rate was $7.47 \% \%\left[(95 \% \mathrm{Cl}, 3.75\right.$ to 14.32$\left.) ; \mathrm{I}^{2}=0.00 \%\right]$. Data limited to randomized studies demonstrated a rebleeding rate of $7.06 \% \%$ [(95\% Cl, 2.73 to 17.05$\left.) ; I^{2}=23.24 \%\right]$. No patients died as a result of rebleeding after treatment with EBL.

\section{EBL versus APC therapy}

Comparison between patients who received non-thermal or thermal therapies revealed no difference in mean age (EBL: $56.27 \pm 8.86$ versus $55.88 \pm 9.54 ; P=0.735)$. There was also no difference in gender between EBL and APC groups (54.03\% versus $55.46 \%$ female; $P=0.824$ ). Additionally, there was no difference in percentage of patients with underlying cirrhosis (EBL: $86.21 \%$ versus APC: $90.38 \%$; $P=0.340$ ) or patients presenting with overt hemorrhage (EBL: $75.00 \%$ versus APC: $63.75 \%$; $P=$ 0.110 ) between the two groups. Mean follow-up was not different for patients who underwent EBL versus thermal therapy $(8.92 \pm 5.38$ versus $9.84 \pm 6.82$ months; $P=0.212)$.

When comparing endoscopic success between EBL versus APC, patients who underwent EBL had a significantly higher endoscopic success rate [OR 6.04 (95\% Cl 1.97 to 18.56; $P=$ 0.002] ( Fig. 3a). This was also accomplished with fewer number of endoscopic treatment sessions (EBL $2.56 \pm 0.81$ versus APC $3.78 \pm 1.17$ sessions; $P<0.001)$. Endoscopic success in randomized studies alone was also higher for EBL compared to APC [OR 5.35 (95\% Cl 1.46 to 19.58; $P=0.011$ ]. Comparison data between EBL versus APC is shown in > Table 2.

Pretreatment hemoglobin was not different between groups (EBL: $7.65 \pm 0.88$ versus APC: $7.55 \pm 0.77 \mathrm{gm} / \mathrm{dL} ; P=0.3501$ ); however, EBL was associated with a greater increase in postprocedure hemoglobin [difference in means 0.59 (95\% Cl 0.17 to $1.00 ; P=0.006]$ ( $\mathbf{F i g . 3 b}$ ). Examination of data from randomized trials, revealed EBL again was associated with a greater increase in hemoglobin when compared to APC [difference in means 0.35 (95\% Cl 0.07 to $0.62 ; P=0.0140$ ]. Endoscopic band ligation was also associated with a greater reduction in transfusions required [difference in means $-1.46(95 \% \mathrm{Cl}$ -2.80 to $-0.12 ; P=0.0330$ ] ( $\triangleright$ Fig. $3 \mathbf{c}$ ). The number of tranfusions required post-EBL was also greater based upon randomized trial data along [difference in means $-2.30(95 \% \mathrm{Cl}-4.11$ to $-2.48 ; P=0.0130]$.

There was no significant difference in adverse events between EBL versus APC [OR 2.07 (95\% Cl, 0.45 to 9.48); $P=$ $0.347]$. Randomized controlled trial adverse events were also not different [OR 2.59 ( $95 \% \mathrm{Cl}, 0.09$ to 72.27); $P=0.576$ ]. With regard to rebleeding, EBL was associated with decreased recurrent bleeding [OR 0.11 ( $95 \% \mathrm{Cl}, 0.04$ to 0.36$)$; $P<0.001$ ( $>$ Fig. 3d). Again, this finding was similar for randomized studies [OR 


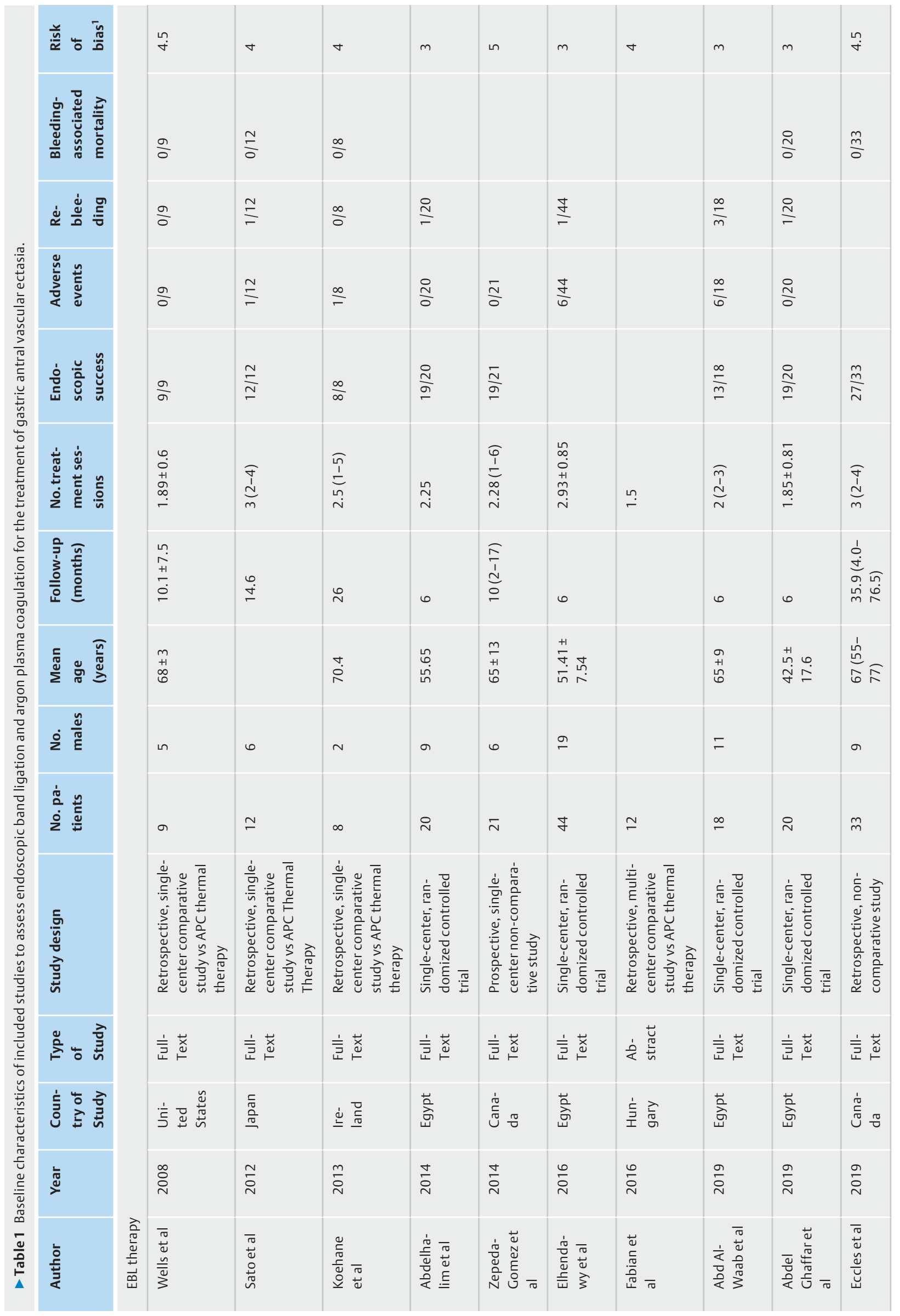




\begin{tabular}{|c|c|c|c|c|c|c|c|c|c|c|}
\hline$\frac{\bar{m}}{\underline{\alpha}} \div \frac{\bar{m}}{0}$ & $\stackrel{\text { ֻn }}{+}$ & & $\stackrel{n}{\sim}$ & $\nabla$ & $\nabla$ & $m$ & $m$ & $\nabla$ & $m$ & $m$ \\
\hline 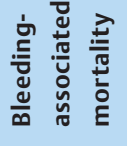 & $\frac{0}{0}$ & & $\frac{m}{o}$ & $\frac{\mathbb{N}}{N}$ & $\stackrel{\frac{1 n}{5}}{0}$ & & & & & $\stackrel{\circ}{\frac{1}{0}}$ \\
\hline 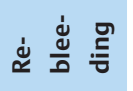 & $\frac{\stackrel{D}{m}}{m}$ & & $\stackrel{m}{i}$ & $\frac{N}{\frac{N}{n}}$ & $\frac{\ln }{\frac{0}{0}}$ & $\frac{\stackrel{\curvearrowright}{N}}{\underline{m}}$ & $\frac{g}{0}$ & & $\stackrel{\infty}{\infty}$ & $\stackrel{\stackrel{\curvearrowright}{N}}{n}$ \\
\hline 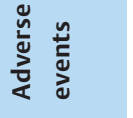 & & & 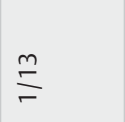 & $\frac{\mathbb{N}}{0}$ & $\stackrel{\frac{n}{2}}{\frac{1}{0}}$ & $\stackrel{\stackrel{2}{0}}{0}$ & $\frac{d}{a}$ & & $\stackrel{\infty}{\frac{\infty}{0}}$ & $\stackrel{\stackrel{1}{0}}{0}$ \\
\hline 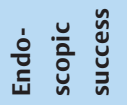 & $\stackrel{\stackrel{2}{\frac{\pi}{g}}}{\frac{1}{\sigma}}$ & & & 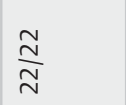 & $\stackrel{\operatorname{nn}}{\stackrel{1}{n}}$ & 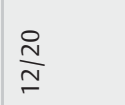 & & & $\stackrel{\infty}{\frac{0}{0}}$ & $\frac{\stackrel{9}{I}}{\underline{I}}$ \\
\hline 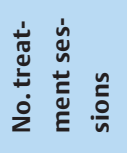 & $\stackrel{\infty}{\sim}$ & & $\begin{array}{l}0 \\
0 \\
+ \\
+1 \\
0 \\
0 \\
\dot{+}\end{array}$ & $\begin{array}{l}\bar{m} \\
\stackrel{1}{n} \\
\stackrel{n}{i}\end{array}$ & $\begin{array}{l}\underset{I}{I} \\
\stackrel{1}{J} \\
\check{+}\end{array}$ & เn & $\begin{array}{l}8 \\
\circ \\
0 \\
+1 \\
\infty \\
+ \\
\text { m. }\end{array}$ & $\stackrel{\widetilde{N}}{\sim}$ & $\underset{d}{\stackrel{f}{d}}$ & $\begin{array}{l}\stackrel{N}{\sim} \\
\stackrel{+}{+1} \\
\stackrel{\sim}{\sim} \\
\dot{\sigma}\end{array}$ \\
\hline 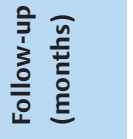 & $\approx$ & & 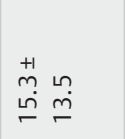 & $\stackrel{\varphi}{\dot{\omega}}$ & $\stackrel{\stackrel{\sim}{\sim}}{ }$ & 0 & 6 & & 0 & 0 \\
\hline 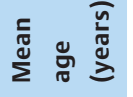 & & & $\begin{array}{l}\overline{7} \\
+1 \\
0 \\
0\end{array}$ & & hે & $\stackrel{7}{i}$ & 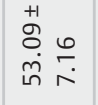 & & $\begin{array}{l}\overline{5} \\
\stackrel{+}{+1} \\
8\end{array}$ & $\stackrel{+}{\stackrel{+}{\sim}} \stackrel{\dot{n}}{\sim}$ \\
\hline$\dot{\partial} \frac{\ddot{0}}{\tilde{E}}$ & & & in & $\sigma$ & $\nabla$ & $\stackrel{\circ}{\circ}$ & $\stackrel{\Perp}{\sim}$ & & 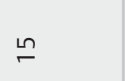 & \\
\hline 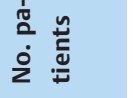 & $\approx$ & & $\stackrel{m}{\sim}$ & $\approx$ & $\stackrel{\Perp}{\sim}$ & iे & J & $\approx$ & $\stackrel{\infty}{\sim}$ & ำ \\
\hline 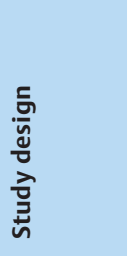 & 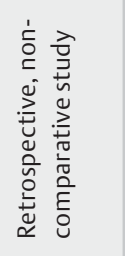 & & 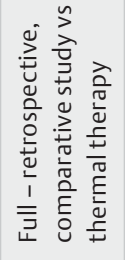 & 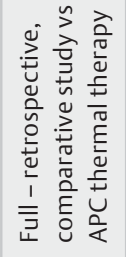 & 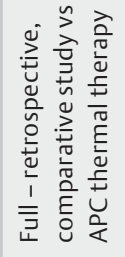 & 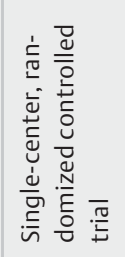 & 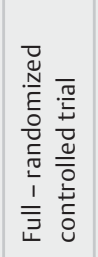 & 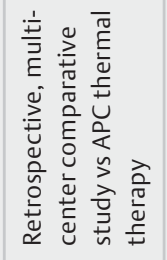 & 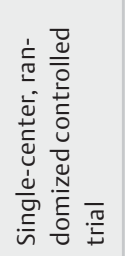 & 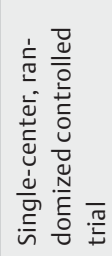 \\
\hline 离む离 & 完荀 & & 言泀 & 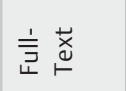 & 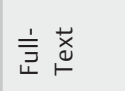 & 言苍 & 言苍 & 它泀 & 言苍 & 言离 \\
\hline 它 㐫 & 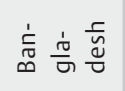 & & 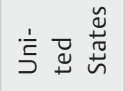 & 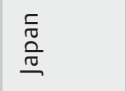 & 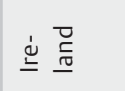 & 言 & 莣 & 空 亮 & 享 & 尝 \\
\hline ঠัँ & ֻे & 衣 & $\stackrel{\infty}{\circ}$ & $\underset{\sim}{\sim}$ & $\stackrel{m}{\stackrel{n}{N}}$ & $\stackrel{+}{\stackrel{\sim}{N}}$ & $\stackrel{0}{\stackrel{0}{2}}$ & $\stackrel{0}{\circ}$ & $\stackrel{o}{\stackrel{2}{N}}$ & 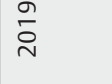 \\
\hline 产 & 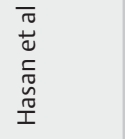 & 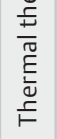 & 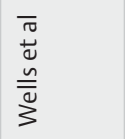 & $\begin{array}{l}\bar{\pi} \\
0 \\
0 \\
0 \\
0 \\
n\end{array}$ & 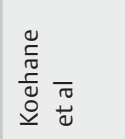 & 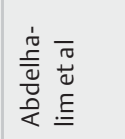 & 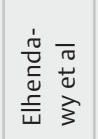 & 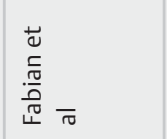 & 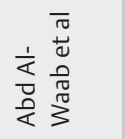 & 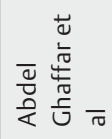 \\
\hline
\end{tabular}


Endoscopic success with EBL for treatment of GAVE

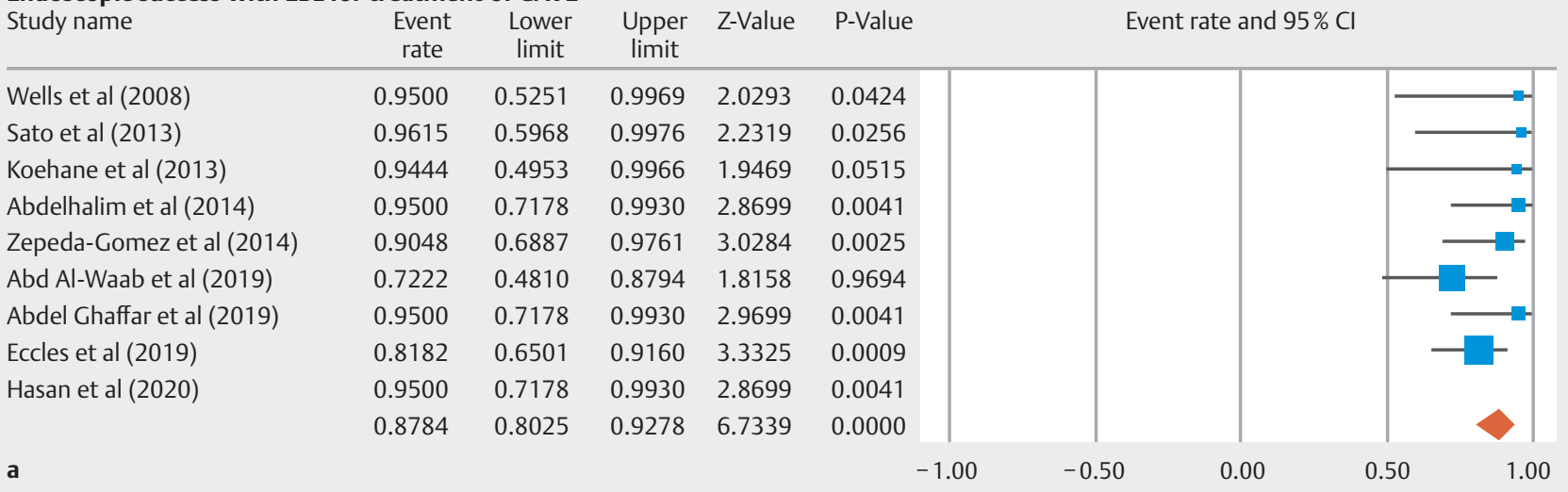

\section{Pre- and post-hemoglobin with EBL for treatment of GAVE}

Study name

Statistics for each study

Difference Standard Variance Lower Upper Z-Value P-Value

Difference in means and $95 \% \mathrm{Cl}$

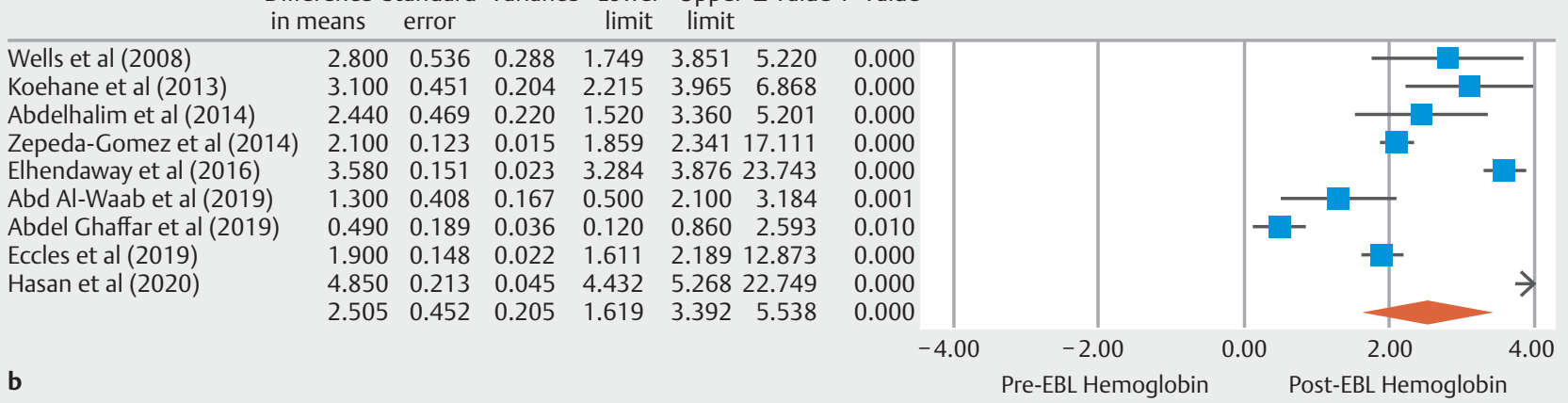

\section{Number of transfusions Pre- and post-EBL for treatment of GAVE}

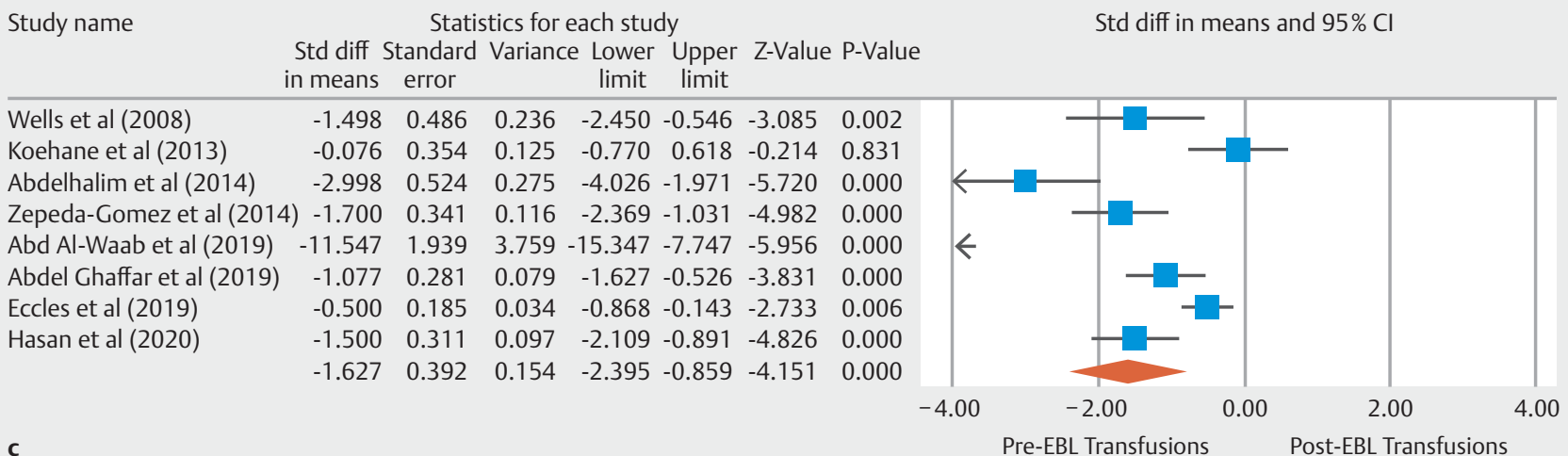

Bleeding-associated hospitalizations Pre- and post-EBL for treatment of GAVE

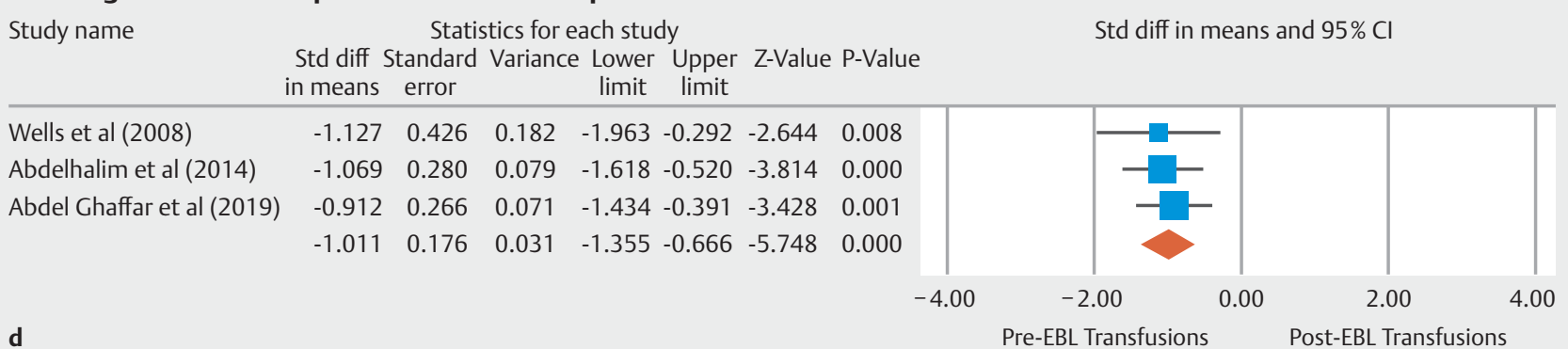

- Fig. 2 a Endoscopic success rate of endoscopic band ligation for the treatment of gastric antral vascular ectasia. $\mathbf{b}$ Change in hemoglobin with of endoscopic band ligation for the treatment of gastric antral vascular ectasia. c Change in red cell transfusions with endoscopic band ligation for the treatment of gastric antral vascular ectasia. $\mathbf{d}$ Rebleeding-associated hospitalization with endoscopic band ligation for the treatment of gastric antral vascular ectasia. 
- Table2 Cumulative data for endoscopic band ligation and comparison to argon plasma coagulation for the treatment of gastric antral vascular ectasia.

\begin{tabular}{|c|c|c|c|}
\hline & Cumulative data:EBL & Comparative data: EBL versus APC & $P$ value \\
\hline Mean age in years & $\begin{array}{l}58.65 \pm 8.85 \\
(8 \text { studies, } n=173 \text { ) }\end{array}$ & $\begin{array}{l}56.27 \pm 8.86 \text { versus } 55.88 \pm 9.54 \\
(6 \text { studies, } n=132 \text { vs } n=117)\end{array}$ & 0.735 \\
\hline No.females & $\begin{array}{l}89(59.39 \%) \\
(8 \text { studies, } n=165)\end{array}$ & $\begin{array}{l}54.03 \% \text { versus } 55.46 \% \\
(6 \text { studies, } n=131 \text { vs } n=132 \text { ) }\end{array}$ & 0.824 \\
\hline No. with cirrhosis & $\begin{array}{l}113(71.97 \%) \\
\text { (7 studies, } \mathrm{n}=133)\end{array}$ & $\begin{array}{l}86.21 \% \text { versus } 90.38 \% \\
(5 \text { studies, } n=103 \text { vs } n=117 \text { ) }\end{array}$ & 0.340 \\
\hline Overt gastrointestinal bleeding & $\begin{array}{l}76(59.39 \%) \\
(7 \text { studies, } n=157)\end{array}$ & $\begin{array}{l}75.00 \% \text { versus } 63.75 \% \\
(5 \text { studies, } n=79 \text { vs } n=03 \text { ) }\end{array}$ & 0.110 \\
\hline Follow-up in months & $\begin{array}{l}14.32 \pm 11.10 \\
(10 \text { studies, } n=207)\end{array}$ & $\begin{array}{l}8.92 \pm 5.38 \text { versus } 9.84 \pm 6.82 \\
(6 \text { studies, } n=132 \text { vs } n=117)\end{array}$ & 0.212 \\
\hline No. treatment sessions & $\begin{array}{l}2.50 \pm 0.49 \\
(11 \text { studies, } n=219)\end{array}$ & $\begin{array}{l}2.56 \pm 0.81 \text { versus } 3.78 \pm 1.17 \\
(8 \text { studies, } n=143 \text { vs } n=174 \text { ) }\end{array}$ & $<0.001$ \\
\hline No. bands applied & $\begin{array}{l}12.40 \pm 3.82 \\
(6 \text { studies, } n=141)\end{array}$ & - & - \\
\hline Endoscopic success & $\begin{array}{l}87.84 \% \\
(95 \% \mathrm{Cl}, 80.25 \text { to } 92.78) \mathrm{I}^{2}=11.96 \% \\
(9 \text { studies, } \mathrm{n}=163)\end{array}$ & $\begin{array}{l}\text { OR } 6.04(95 \% \mathrm{Cl} 1.97 \text { to } 18.56) \\
\text { (5 studies, } \mathrm{n}=78 \text { vs } \mathrm{n}=95)\end{array}$ & 0.002 \\
\hline Change in hemoglobin & $\begin{array}{l}2.23 \mathrm{gm} / \mathrm{dL} \\
(95 \% \mathrm{Cl}, 1.39 \text { to } 3.07) \mathrm{I}^{2}=91.00 \% \\
(8 \text { studies, } \mathrm{n}=173)\end{array}$ & $\begin{array}{l}\text { Mean diff } 0.59(95 \% \mathrm{Cl} 0.17 \text { to } 1.00) \\
\text { (6 studies, } n=119 \text { vs } n=130)\end{array}$ & 0.006 \\
\hline Change in transfusion requirements & $\begin{array}{l}-1.63 \text { units } \\
(95 \% \mathrm{Cl},-2.39 \text { to }-0.86) \mathrm{I}^{2}=89.39 \% \\
(6 \text { studies, } \mathrm{n}=108)\end{array}$ & $\begin{array}{l}\text { Mean diff }-1.46(95 \% \mathrm{Cl}-2.80 \text { to }-0.12) \\
\text { ( } 5 \text { studies, } \mathrm{n}=75 \text { vs } \mathrm{n}=86)\end{array}$ & 0.033 \\
\hline Change in number of hospitalizations & $\begin{array}{l}-1.01 \\
(95 \% \mathrm{Cl},-1.35 \text { to }-0.67) \mathrm{I}^{2}=0.00 \% \\
(3 \text { studies, } \mathrm{n}=49)\end{array}$ & - & - \\
\hline Adverse events & $\begin{array}{l}10.90 \% \\
(95 \% \mathrm{Cl}, 5.14 \text { to } 21.65) \mathrm{I}^{2}=38.23 \% \\
(8 \text { studies, } \mathrm{n}=152)\end{array}$ & $\begin{array}{l}\text { OR } 2.07(95 \% \mathrm{Cl}, 0.45 \text { to } 9.48) \\
\text { ( } 7 \text { studies, } \mathrm{n}=131 \text { vs } \mathrm{n}=152 \text { ) }\end{array}$ & 0.347 \\
\hline Rebleeding events & $\begin{array}{l}9.00 \% \\
(95 \% \mathrm{Cl}, 5.02 \text { to } 15.62) \\
\mathrm{I}^{2}=0.00 \% \\
(8 \text { studies, } \mathrm{n}=153)\end{array}$ & $\begin{array}{l}\text { OR } 0.11(95 \% \mathrm{Cl}, 0.04 \text { to } 0.36) \\
\text { ( } 7 \text { studies, } n=131 \text { vs } n=152 \text { ) }\end{array}$ & $<0.001$ \\
\hline Bleeding-associated mortality & $\begin{array}{l}3.09 \% \\
(95 \% \mathrm{Cl}, 1.00 \text { to } 9.16) \\
\mathrm{I}^{2}=0.00 \% \\
(6 \text { studies, } \mathrm{n}=104)\end{array}$ & $\begin{array}{l}\text { OR } 0.33(95 \% \mathrm{Cl}, 0.02 \text { to } 7.40 \text { ) } \\
\text { ( } 4 \text { studies, } n=49 \text { vs } n=70 \text { ) }\end{array}$ & 0.483 \\
\hline
\end{tabular}

0.17 (95\% Cl, 0.04 to 0.82$) ; P=0.027]$. There was no statistically significant difference found for bleeding-associated mortality between groups [OR $0.33(95 \% \mathrm{Cl}, 0.02$ to 7.4$) ; P=0.483$ ].

\section{Treatment-naïve versus APC-refractory GAVE}

A total of six studies ( $n=127$ patients) included patients with prior APC therapy, of which 48 patients (37.80\%) reported APC-refractory GAVE. Individual reporting of data from these patients was not possible; however, data from these six studies were compared to the remaining 5 studies that included only treatment naïve patients. Based upon univariate meta-regres- sion, there was no difference in endoscopic success [OR 0.94 (95\% Cl 0.26 to 3.46; $P=0.927$ ] between groups (Supplemental Fig. 1). Mean improvement in hemoglobin was not different between treatment naïve and APC-refractory patients though there was a trend towards more improvement among patients with no prior treatment [OR $0.29(95 \% \mathrm{Cl} 0.08$ to $1.05 ; P=$ 0.060] (Supplemental Fig.2). Treatment naïve patients did, however, experience a greater reduction in transfusions compared to patients with APC-refractory GAVE [OR $0.20(95 \% \mathrm{Cl}$ 0.04 to 0.96; $P=0.045$ ] (Supplemental Fig. 3). Adverse events were not statistically different between studies that included 
Endoscopic success with EBL vs APC for treatment of GAVE

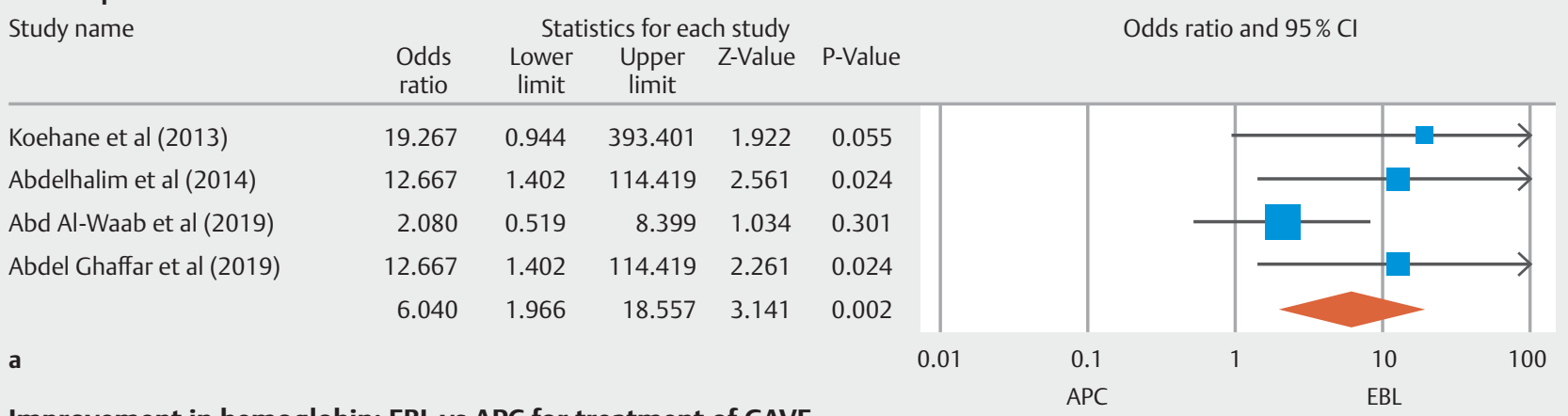

\section{Improvement in hemoglobin: EBL vs APC for treatment of GAVE}

Study name

Statistics for each study

Difference Standard Variance Lower Upper Z-Value P-Value

Difference in means and $95 \% \mathrm{Cl}$

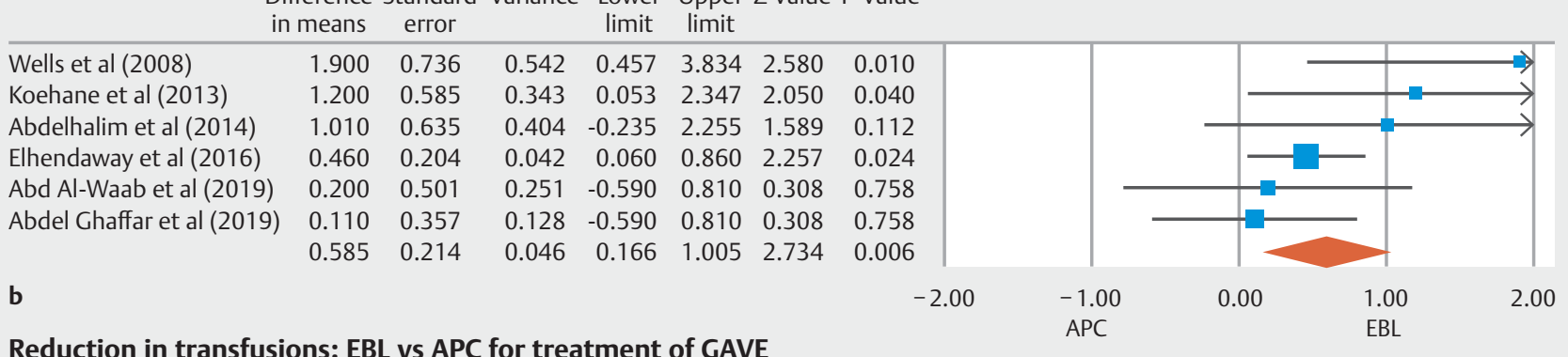

Reduction in transfusions: EBL vs APC for treatment of GAVE

Study name Statistics for each study

Difference Standard Variance Lower Upper Z-Value P-Value

Difference in means and $95 \% \mathrm{Cl}$

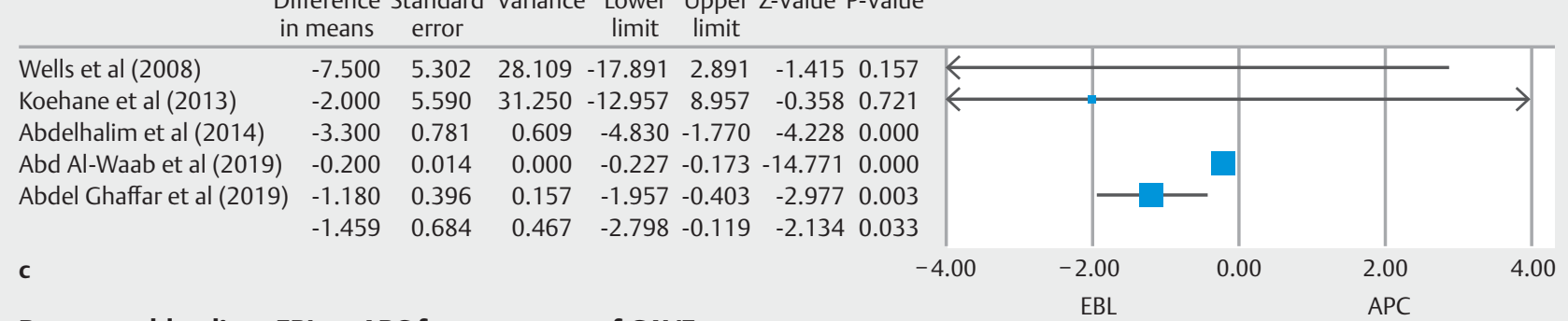

Recurrent bleeding: EBL vs APC for treatment of GAVE

$\begin{array}{lcccccc}\text { Study name } & \begin{array}{c}\text { Odds } \\ \text { ratio }\end{array} & \begin{array}{c}\text { Sower } \\ \text { limit }\end{array} & \begin{array}{c}\text { Upper } \\ \text { limit }\end{array} & \text { Z-Value } & \text { P-Value } \\ & 0.046 & 0.002 & 0.946 & -1.996 & 0.046 \\ \text { Wells et al (2008) } & 0.042 & 0.005 & 0.397 & -2.771 & 0.006 \\ \text { Sato et al (2012) } & 0.028 & 0.003 & 0.259 & -3.159 & 0.002 \\ \text { Abdelhalim et al (2014) } & 3.069 & 0.122 & 77.410 & 0.681 & 0.496 \\ \text { Elhendaway et al (2016) } & 0.250 & 0.053 & 1.177 & -1.754 & 0.080 \\ \text { Abd Al-Waab et al (2019) } & 0.098 & 0.011 & 0.892 & -2.062 & 0.039 \\ \text { Abdel Ghaffar et al (2019) } & 0.113 & 0.036 & 0.360 & -3.695 & 0.000\end{array}$

d

Odds ratio and $95 \% \mathrm{Cl}$

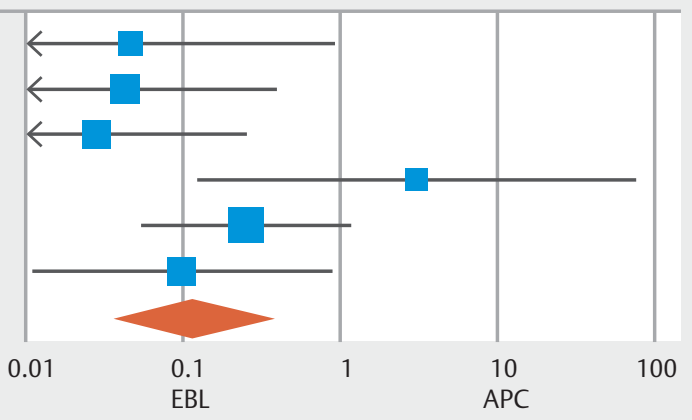

- Fig. 3 a Endoscopic success: endoscopic band ligation and comparison to argon plasma coagulation for the treatment of gastric antral vascular ectasia. b Change in hemoglobin: endoscopic band ligation and comparison to argon plasma coagulation for the treatment of gastric antral vascular ectasia. c Change in red cell transfusions: endoscopic band ligation and comparison to argon plasma coagulation for the treatment of gastric antral vascular ectasia. $\mathbf{d}$ Change in recurrent bleeding: endoscopic band ligation and comparison to argon plasma coagulation for the treatment of gastric antral vascular ectasia. 
patients with and without prior APC therapy [OR $1.60(95 \% \mathrm{Cl}$ 0.28 to 9.21)] (Supplemental Fig. 4).

\section{Risk of bias assessment}

Quality assessment for each study shown in > Table 1. Visual inspection of the funnel plot demonstrated that smaller and statistically insignificant studies appeared to be missing likely due

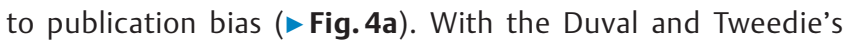
trim and fill method, overall endoscopic success of EBL for the treatment of GAVE was slightly decreased from $87.84 \%$ (95\% $\mathrm{Cl}, 80.25$ to 92.78$)$ to $84.55 \%(95 \% \mathrm{Cl} 75.80$ to 90.53$)$ though this was not statistically significant due to the presence of overlapping confidence intervals ( $\triangleright$ Fig.4b).

\section{Discussion}

While GAVE encompasses approximately $4 \%$ of all upper gastrointestinal, non-variceal bleeding etiologies, it remains a condition that is difficult to treat and often associated with profound iron deficiency anemia. Despite thermal therapy with APC being a first-line treatment strategy, this systematic review and meta-analysis demonstrated EBL is associated with a higher rate of ectasia eradication, greater increase in post-procedure hemoglobin, and lower rate of rebleeding. This greater endoscopic success rate was accomplished with fewer treatment sessions as well, with no difference in adverse events compared to APC. Based upon these results, EBL appears to be a safe and effective primary and refractory therapy for the treatment of GAVE.

First described by Rider and colleagues in 1953, GAVE remains a challenging condition to successful treat, with many patient remaining transfusion dependent despite iron supplementation [7]. As the precise etiology of GAVE remains uncertain, multiple treatment modalities have been attempted. While pharmacotherapy has been shown to be ineffective for GAVE, endoscopic management, most commonly with thermal-based therapies such as APC and, less commonly, RFA have traditionally been the preferred treatment modality [4751]. Yet, based upon this recent systematic review and meta-analysis, EBL appears to be an effective therapy for GAVE.

Available evidence has shown endoscopic treatment of GAVE with RFA may have a better efficacy and tolerability as compared to APC, perhaps due to the difference in thermal technique $[17,18]$. Application of RFA involves high frequency alternating electrical current delivered locally to tissue which may provide a more controlled depth of thermal coagulative necrosis, as compared to APC which is a non-contact technique with more variable depth of coagulation [50,52]. However, given the submucosal involvement of GAVE, it would therefore make sense that EBL may provide better or equivalent outcomes and improved endoscopic success, along with fewer treatment sessions required.

These findings, including higher operator-reported endoscopic success, fewer endoscopic treatment sessions required, lower adverse event rates, and familiarity with the band ligation device, suggest EBL may be a more cost-effective therapy for patients with GAVE. However, at this time, there is no cost-ef-
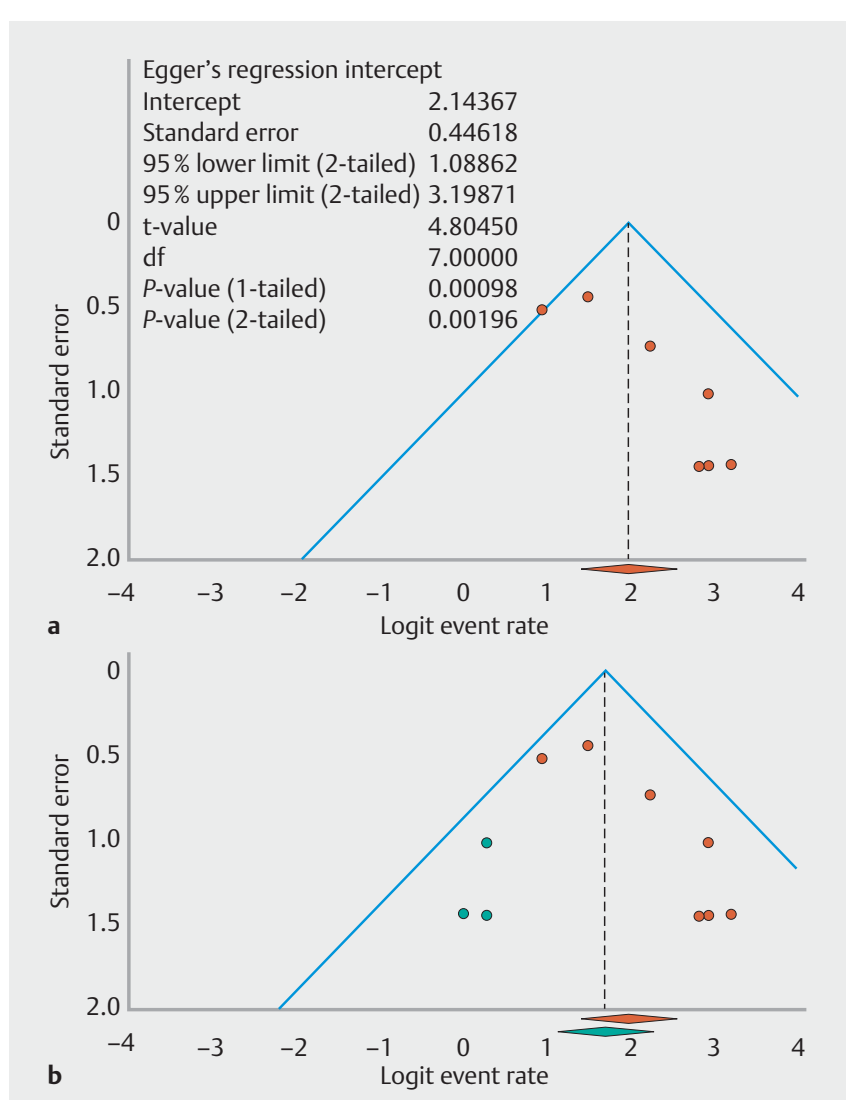

- Fig. 4 a Funnel plot of publication bias and egger's regression test for included studies. b Duval and Tweedie's trim and fill method to assess publication bias.

fectiveness data to support this claim. Conventionally, EBL has been considered a salvage therapy, for individuals that may not response to prior treatment with APC. While $37.80 \%$ of patients included in this meta-analysis had GAVE that was refractory to APC, a majority of patients received EBL therapy without prior thermal treatment, perhaps suggesting EBL may be considered an early treatment option for GAVE. One randomized study of 30 participants is underway comparing EBL versus APC for treatment of GAVE (NCT01601639) [53]. However, future, higher-powered randomized studies are needed to directly compare EBL versus APC, as well as RFA among patients with both treatment-naive and refractory GAVE.

A previous meta-analysis, including a total of five studies (n = 207 patients - EBL: 93 patients vs APC: 114 patients) has recently been published on this topic [54]. While this study included fewer studies and shorter duration of follow-up, these authors found similar results regarding the effectiveness of EBL vs APC, including significantly lower transfusion requirements and treatment sessions required to achieve eradication with no differences in adverse events. However, among EBL and APC patients with comparable pre-treatment hemoglobin levels, we found EBL to be associated with a significantly greater increase in post-procedure hemoglobin, different from the previous meta-analysis and likely a result of greater power associated with our study. In this current manuscript, we also com- 
pared baseline characteristics of EBL and APC patients and found no differences in age, gender, percentage of patients with cirrhosis, number with overt gastrointestinal hemorrhage, and duration of follow-up, thereby improving the interpretability and generalizability of our findings.

In this systematic review and meta-analysis, we performed additional regression analyses to determine if EBL outcomes differed based upon prior APC therapy. Importantly, based upon our regression analyses, we found no statistically significant differences in endoscopic success, change in hemoglobin, or adverse events among studies that included patients with and without APC-refractory GAVE. It should be noted that there was a trend toward greater improvement in post-EBL hemoglobin among treatment naïve patients $(P=0.060)$ and treatment naïve patients showed a significantly greater reduction in transfusion requirements compared to APC-refractory patients. Despite this, these results should be interpreted with some caution given the lack of individualized data reported and need for dedicated studies to examine this critically important clinical question.

This systematic review and meta-analysis is not without limitations. Firstly, given the cumulative nature of this systematic review and meta-analysis, as well as the variability in type of GAVE and comorbid conditions of patients, it is not surprising heterogeneity was significant for multiple study outcomes. Unfortunately, regression analyses could not be performed to identify if factors such as presence or absence of cirrhosis, acute hemorrhage, type or severity of GAVE (watermelon stomach versus honeycomb appearance), as well as a nodular or flat appearance may impact treatment strategies. Furthermore, observational studies were included alongside randomized trials - introducing the possibility of selection bias and confounding - however, sensitivity analyses were performed for only randomized controlled studies. Additionally, significant variability was noted between study authors' definitions of eradication and subjective visual evidence of endoscopic improvement (i.e., endoscopic success). This variability and lack of standardization in outcome underscores the need for a well-defined clinical or endoscopic grading system; however, objective measures regarding clinical outcomes such as hemoglobin level, transfusion requirements, and adverse events were also reported. While a histologic grading system has been established for GAVE, this is not routinely used in clinical practice and was not reported in the included studies [55, 56]. Lastly, it should be emphasized these results are reported as ORs and not as relative risk, which may overestimate our findings [57].

Despite these limitations, our study has several strengths. Chiefly, this systematic review and meta-analysis is the first to analyze EBL for the treatment of GAVE, and directly compares outcomes to APC among a population of patients that are similar. Additionally, given the familiarity of endoscopists with band ligation for esophageal variceal treatment, there is a minimal learning curve to expand this treatment to GAVE. Furthermore, the inclusion of patients with previous APC may actually under-estimate the true effectiveness of EBL. Lastly, inclusion of endoscopic and clinical outcomes including hemoglobin, transfusion dependency, as well as number of sessions for treatment are highly relevant for clinicians and readily translate to real-world clinical practice.

\section{Conclusions}

Based upon the results of this systematic review and meta-analysis, EBL is a safe and effective modality for the treatment of GAVE. Comparing this strategy to traditional thermal therapy, EBL was associated with a higher endoscopic success rate and improved clinical success including a greater increase in hemoglobin, reduction in transfusion dependency, and decreased rate of rebleeding. Ultimately, the endoscopic and clinical success of EBL suggest an emerging role for the use of this modality in patients with GAVE.

\section{Acknowledgements}

This work was funded, at least in part, by the NIH grant T32 DK007533-35.

\section{Competing interests}

The authors declare that they have no conflict of interest.

\section{References}

[1] Jabbari M, Cherry R, Lough JO et al. Gastric antral vascular ectasia: the watermelon stomach. Gastroenterology 1984; 87: 1165-1170

[2] Burak KW, Lee SS, Beck PL. Portal hypertensive gastropathy and gastric antral vascular ectasia (GAVE) syndrome. Gut 2001; 49: 866-872

[3] Spahr L, Villeneuve JP, Dufresne MP et al. Gastric antral vascular ectasia in cirrhotic patients: absence of relation with portal hypertension. Gut 1999; 44: 739-742

[4] Charneau J, Petit R, Cales P et al. Antral motility in patients with cirrhosis with or without gastric antral vascular ectasia. Gut 1995; 37: 488-492

[5] Quintero E, Pique JM, Bombi JA et al. Gastric mucosal vascular ectasias causing bleeding in cirrhosis. A distinct entity associated with hypergastrinemia and low serum levels of pepsinogen I. Gastroenterology 1987; 93: 1054-1061

[6] Lowes JR, Rode J. Neuroendocrine cell proliferations in gastric antral vascular ectasia. Gastroenterology 1989; 97: 207-212

[7] Rider JA, Klotz AP, Kirsner JB. Gastritis with veno-capillary ectasia as a source of massive gastric hemorrhage. Gastroenterology 1953; 24: $118-123$

[8] Ito M, Uchida Y, Kamano $S$ et al. Clinical comparisons between two subsets of gastric antral vascular ectasia. Gastrointest Endosc 2001; 53: 764-770

[9] Lee Fl, Costello F, Flanagan N et al. Diffuse antral vascular ectasia. Gastrointest Endosc 1984; 30: 87-90

[10] Kruger R, Ryan ME, Dickson KB et al. Diffuse vascular ectasia of the gastric antrum. Am J Gastroenterol 1987; 82: 421-426

[11] Dulai GS, Jensen DM, Kovacs TO et al. Endoscopic treatment outcomes in watermelon stomach patients with and without portal hypertension. Endoscopy 2004; 36: 68-72

[12] Gretz JE, Achem SR. The watermelon stomach: clinical presentation, diagnosis, and treatment. Am J Gastroenterol 1998; 93: 890-895 
[13] Park RH, Russell RI. Watermelon stomach. Br J Surg 1991; 78: 395396

[14] Sebastian S, O’Morain CA, Buckley MJ. Review article: current therapeutic options for gastric antral vascular ectasia. Aliment Pharmacol Therap 2003; 18: 157-165

[15] Yusoff I, Brennan F, Ormonde D et al. Argon plasma coagulation for treatment of watermelon stomach. Endoscopy 2002; 34: 407-410

[16] Zepeda-Gomez S. Endoscopic treatment for gastric antral vascular ectasia: current options. GE Port J Gastroenterol 2017; 24: 176-182

[17] McCarty TR, Rustagi T. New indications for endoscopic radiofrequency ablation. Clin Gastroenterol Hepatol 2018; 16: 1007-1017

[18] McCarty TR, Rustagi T. Comparative effectiveness and safety of radiofrequency ablation versus argon plasma coagulation for treatment of gastric antral vascular ectasia: a systematic review and metaanalysis. J Clin Gastroenterol 2019; 53: 599-606

[19] Tantau M, Crisan D. Is endoscopic band ligation the gold standard for gastric antral vascular ectasia? Endosc Int Open 2019; 7: E1630E1631

[20] Liberati A, Altman DG, Tetzlaff ] et al. The PRISMA statement for reporting systematic reviews and meta-analyses of studies that evaluate health care interventions: explanation and elaboration. Ann Int Med 2009; 151: W65-W94

[21] Stroup DF, Berlin JA, Morton SC et al. Meta-analysis of observational studies in epidemiology: a proposal for reporting. Meta-analysis Of Observational Studies in Epidemiology (MOOSE) group. JAMA 2000; 283: 2008-2012

[22] DerSimonian R, Laird N. Meta-analysis in clinical trials. Controlled Clin Trials 1986; 7: 177-188

[23] Stuart A, Ord JK. Kendall's Advanced Theory of Statistics. 6th ed. London: Edward Arnold; 1994

[24] Riley RD, Higgins JPT, Deeks JJ. Research Methods \& reporting: interpretation of random effects meta-analyses. Br Med J 2011; 342: d549

[25] Higgins JP, Thompson SG, Deeks J] et al. Measuring inconsistency in meta-analyses. BMJ 2003; 327: 557-560

[26] Overton RC. A comparison of fixed-effects and mixed (random-effects) models for meta-analysis tests of moderator variable effects. Psychologl Methods 1998; 3: 354-379

[27] Wells G, Shea B, O'Connell D et al. The Newcastle-Ottawa Scale (NOS) for assessing the quality of nonrandomised studies in meta-analysis. 3rd Symposium on Systematic Reviews: Beyond the Basics; July 3-5. Oxford: 2000: Available at (Accessed 24.11.2019): http://www.ohri. ca/programs/clinical_epidemiology/oxford.asp

[28] Higgins JPT, Altman DG, Sterne JAC. Cochrane Handbook for Systematic Reviews of Interventions. Higgins JPT; http://www.cochranehandbook.org

[29] Fuccio L, Zagari RM, Serrani M et al. Endoscopic argon plasma coagulation for the treatment of gastric antral vascular ectasia-related bleeding in patients with liver cirrhosis. Digestion 2009; 79: 143-150

[30] Borenstein M, Hedges LV, Higgins JP et al. Introduction to meta-analysis. Hoboken: John Wiley \& Sons; 2011

[31] Higgins ], Thompson SG, Spiegelhalter DJ. A re-evaluation of randomeffects meta-analysis. J R Statist Soc A 2009; 172: 137-159

[32] Borenstein M, Higgins JP, Hedges LV et al. Basics of meta-analysis: I(2) is not an absolute measure of heterogeneity. Res Synth Methods 2017; 8: 5-18

[33] Chiu YC, Lu LS, Wu KL et al. Comparison of argon plasma coagulation in management of upper gastrointestinal angiodysplasia and gastric antral vascular ectasia hemorrhage. BMC Gastroenterol 2012; 12: 67

[34] Chaves DM, Sakai P, Oliveira CV et al. Watermelon stomach: clinical aspects and treatment with argon plasma coagulation. Arquivos de Gastroenterologia 2006; 43: 191-195
[35] Boltin D, Gingold-Belfer R, Lichtenstein L et al. Long-term treatment outcome of patients with gastric vascular ectasia treated with argon plasma coagulation. Europ J Gastroenterol Hepatol 2014; 26: 588593

[36] Wells CD, Harrison ME, Gurudu SR et al. Treatment of gastric antral vascular ectasia (watermelon stomach) with endoscopic band ligation. Gastrointest Endosc 2008; 68: 231-236

[37] Sato T, Yamazaki K, Akaike J. Endoscopic band ligation versus argon plasma coagulation for gastric antral vascular ectasia associated with liver diseases. Diges Endosc 2012; 24: 237-242

[38] Keohane J, Berro W, Harewood GC et al. Band ligation of gastric antral vascular ectasia is a safe and effective endoscopic treatment. Digest Endosc 2013; 25: 392-396

[39] Abdelhalim H, Mostafa I, Salah Abdelbary M et al. Endoscopic band ligation versus argon plasma coagulation for the treatment of gastric antral vascular ectasia in egyptian patients with liver cirrhosis. World J Med Sci 2014; 10: 357-361

[40] Zepeda-Gomez S, Sultanian R, Teshima C et al. Gastric antral vascular ectasia: a prospective study of treatment with endoscopic band ligation. Endoscopy 2015; 47: 538-540

[41] Elhendawy M, Mosaad S, Alkhalawany W et al. Randomized controlled study of endoscopic band ligation and argon plasma coagulation in the treatment of gastric antral and fundal vascular ectasia. United Europ Gastroenterol J 2016; 4: 423-428

[42] Fabian A, Bor R, Szabo E et al. Endoscopic treatment of gastric antral vascular ectasia: a retrospective multicentre clinical study. United Europ Gastroenterol J 2016; 4: 5: A134

[43] Abd Al-Wahab NA, Amer kA, Ibrahim AY. Argon plasma coagulation versus endoscopic band ligation in treatment of gastric antral vascular ectasia in cirrhotic patients in Zagazig University Hospitals. AfroEgypt J Infect Endem Dis 2019; 9: 176-184

[44] Abdel Ghaffar MM, Abd El Maguid HM. Endoscopic band ligation versus argon plasma coagulation in management of bleeding from gastric antral vascular ectasia in patients with portal hypertension. J Med Sci Res 2019; 2: 214-219

[45] Eccles ], Falk V, Montano-Loza AJ et al. Long-term follow-up in patients with gastric antral vascular ectasia (GAVE) after treatment with endoscopic band ligation (EBL). Endosc Int Open 2019; 7: E1624E1629

[46] Hasan MH, Habib RB, Das SC. Endoscopic band ligation: as initial therapy for gastric antral vascular ectasia. Dig Endosc 2020; 32: 83

[47] Tran A, Villeneuve JP, Bilodeau M et al. Treatment of chronic bleeding from gastric antral vascular ectasia (GAVE) with estrogen-progesterone in cirrhotic patients: an open pilot study. Am J Gastroenterol 1999; 94: 2909-2911

[48] Barbara G, De Giorgio R, Salvioli B et al. Unsuccessful octreotide treatment of the watermelon stomach. J Clin Gastroenterol 1998; 26: 345-346

[49] Park RH, Danesh B], Upadhyay R et al. Gastric antral vascular ectasia (watermelon stomach) - therapeutic options. Postgrad Med J 1990; 66: 720-723

[50] Fuccio L, Mussetto A, Laterza L et al. Diagnosis and management of gastric antral vascular ectasia. World J Gastrointest Endosc 2013; 5: $6-13$

[51] Novitsky YW, Kercher KW, Czerniach DR et al. Watermelon stomach: pathophysiology, diagnosis, and management. J Gastrointest Surg 2003; 7: 652-661

[52] Ganz RA, Utley DS, Stern RA et al. Complete ablation of esophageal epithelium with a balloon-based bipolar electrode: a phased evaluation in the porcine and in the human esophagus. Gastrointest Endosc 2004; 60: 1002-1010 
[53] Zepeda-Gomez S. Endoscopic band ligation versus argon plasma coagulation for the treatment of gastric antral vascular ectasia: a randomized clinical trial. United States National Library of Medicine NCT01601639; Available at (Accessed 30.08.2020): https://clinicaltrials.gov/ct2/show/NCT01601639

[54] Chalhoub JM, Umar J, Groudan K et al. Endoscopic band ligation compared to thermal therapy for gastric antral vascular ectasia: A systematic review and meta-analysis. United European Gastroenterol J 2020: doi:10.1177/2050640620975243
[55] Gilliam JH 3rd, Geisinger KR, Wu WC et al. Endoscopic biopsy is diagnostic in gastric antral vascular ectasia. The "watermelon stomach". Dig Dis Sci 1989; 34: 885-888

[56] Payen JL, Cales P, Voigt JJ et al. Severe portal hypertensive gastropathy and antral vascular ectasia are distinct entities in patients with cirrhosis. Gastroenterology 1995; 108: 138-144

[57] Davies HT, Crombie IK, Tavakoli M. When can odds ratios mislead? BMJ 1998; 316: 989-991 